\title{
Prevalence of Myopia in Preschool and School Children in the Municipality of Prishtina in Kosovo
}

\author{
Shoshi Flaka1*, Hoxha-Shoshi Mire², Shoshi Fitore², Shoshi Fjolla², Shoshi Avdyl ${ }^{3}$ \\ ${ }^{1}$ Department of Clinical Medicine, Faculty of Medicine, University of Prishtina, Prishtina, Republic of Kosova \\ ${ }^{2}$ College of Medical Sciences "REZONANCA", Prishtina, Republic of Kosova \\ ${ }^{3} \mathrm{AAB}$ College, Prishtina, Republic of Kosova \\ Email: ${ }^{\star}$ flakashoshi@gmail.com
}

How to cite this paper: Flaka, S., Mire, H.-S., Fitore, S., Fjolla, S. and Avdyl, S. (2020) Prevalence of Myopia in Preschool and School Children in the Municipality of Prishtina in Kosovo. Open Journal of Ophthalmology, 10, 33-43.

https://doi.org/10.4236/ojoph.2020.101005

Received: November 19, 2019

Accepted: January 3, 2020

Published: January 6, 2020

Copyright $\odot 2020$ by author(s) and Scientific Research Publishing Inc. This work is licensed under the Creative Commons Attribution International License (CC BY 4.0).

http://creativecommons.org/licenses/by/4.0/

\begin{abstract}
Introduction: Myopia is the refractive anomaly of the eye in which the conjugate focus of the retina is at some finite point in front of the eye, when the eye is not accommodating. Myopia is else known as short-sightedness and is considered as one of the most frequent causes of reduced vision especially in adolescents. Adolescence is one of the life periods when most cases are diagnosed with myopia. Purpose: The aim of this study was to identify myopia in pre-school and school children (3 - 9 years old in Prishtina), to determine the prevalence of myopia among other refractive anomalies in cases included in the study; compare the prevalence of myopia in this population in Prishtina to other countries in the world; determine the effect of hereditary and socio-economic factors on the prevalence of myopia; and determine the degrees of myopia in our cases included in our study. Materials and Methods: This was a cross-sectional study involving 1027 pre-school children and pupils from 4 schools in Prishtina, aged 3 - 9 years old, who were screened for refractive anomalies, with a special focus on the incidence of myopia in this age group. The data were collected by screening children in the institutions of pre-school and primary school education, including 2 primary schools and two kindergarten during a two-year period 2010-2012 in Prishtina. Results: On the screening of pre-school and school children for refractive anomalies, were included 1027 subjects of ages 3 - 9 years old. Of the 1027 children screened $536(52.2 \%)$ were male and $491(47.8 \%)$ were female. Statistically, the prevalence of refractive anomalies in the total population studied is significant based on the resulting value $(\mathrm{P}<0.0001)$. In general, the prevalence of refractive anomalies in this study results in 164/103 with an interval of 141/103 in $186 / 103$ for $95 \%$ CI. Based on the age, out of 168 patients identified with re-
\end{abstract}


fractive anomalies, the prevalence of refractive anomalies was $9.9 \%$ in the patients of age 3 and $21.4 \%$ on the patients of age 7 . The prevalence of myopia as a specific refractive anomaly was present in 33 cases $3.4 \%$. Other patients were diagnosed with hypermetropia 37 cases $(3.8 \%)$ and with astigmatism 44 cases (4.5\%). Out of 33 cases with myopia, 20 cases or $60 \%$ were diagnosed with a slight degree myopia (myopia of first degree or -1.0 to -3.0 DS). 13 cases were diagnosed with intermediate degree myopia ( -3 to -6 DS). There were no cases with severe myopia identified in this study. Conclusions: The Prishtina study is a report of prevalence of myopia among pre-school and school-age children in the municipality. The study reveals that refractive error and myopia were significantly common finding among the study group, and the prevalence was found to be even higher in children within the school age-group. The number of newly diagnosed myopia was significant, suggesting the need for a robust school eye health programme, regular assessment of school children for refractive error and provision of timely refractive corrections.

\section{Keywords}

Myopia, Prevalence, Refractive Anomalies, School Children, Refractive Errors

\section{Introduction}

Myopia is the refractive anomaly of the eye in which the conjugate focus of the retina is at some finite point in front of the eye, when the eye is not accommodating. It can also be described as the refractive condition in which parallel light rays from an object at optical infinity are focused by the eye in front of the retina, with accommodation relaxed [1]. Myopia is else known as short-sightedness and is considered as one of the most frequent causes of reduced vision especially in adolescents. Adolescence is one of the life periods when most cases are diagnosed with myopia.

It is characterized by blurring of objects viewed at a distance, and is commonly the result of abnormal elongation of the eyeball which causes the refractive image formed by the cornea and the lens to fall in front of the photoreceptors of the retina [2]. A person with uncorrected myopia cannot see distant objects clearly, but close objects are seen clearly.

There are various classifications of myopia such as clinical, degree of myopia and age of onset. Based on the clinical classification, there are these types of myopia: simple myopia, nocturnal myopia, pseudomyopia, degenerative myopia, and induced (acquired) myopia.

By the age of onset, there is congenital, youth onset, early adult-onset, late adult-onset myopia. By the degree, myopia is classified as mild (low), intermediate (medium) and severe (high) myopia. The focus of this paper is on prevalence of myopia among children of school age and pre-schoolers; and for 
the purposes of this study, myopia is classified based on the degree of myopia, which in turn is based on the diopteric power obtained after refraction of the patients' eye.

Based on the visual acuity myopia is classified in three different degrees: mild myopia, intermediate myopia and severe myopia.

1) Slight myopia up to -3 DS;

2) Intermediate myopia -3 DS to -6 DS;

3) Severe myopia from -7 DS.

The prevalence of myopia varies with age and other factors. When examined without the aid of cycloplegic agents, a significant number of infants are found to have some degree of myopia.

Their myopia tends to decrease, and most such infants reach emmetropia by 2 - 3 years of age. The prevalence of myopia is high in premature infants [3] [4].

An important risk factor for the development of simple myopia is a family history of myopia [5] [6] [7].

\section{Purpose of the Study}

The main purposes of this study were:

- To identify myopia in pre-school and school children (3 - 9 years old in Prishtina).

- To determine the prevalence of myopia among other refractive anomalies in cases included in the study.

- To compare the prevalence of myopia in this population in Prishtina to other countries in the world.

- To determine the effect of hereditary and socio-economic factors on the prevalence of myopia.

- To determine the degrees of myopia in our cases included in our study.

- Treatment of myopia and the evaluation of the short and long-term outcome of the treatment.

\section{Materials and Methods}

This research included 1027 subjects - children of age 3 - 9 years old in Prishtina who were screened for refractive anomalies, with a special focus on the incidence of myopia in this group-age.

The data were collected by screening children 3 - 9 years old in the institutions of pre-school and primary school education, from 2 primary schools and 2 kindergarten during a two year period 2010-2012 in Prishtina.

For the data collection we have used the data collected by the questionnaire designed for the screening project during 2010-2012, the questionnaires included the general information such as the name, surname, date of birth, short medical history with a focus on the ocular health of the screened subjects and the data regarding their ocular health such as vision acuity, presence or non-presence of refractive anomalies or other eye pathologies. 
Prior to screening we were given the permission from the ethical council of the Ministry of Education, Science and Technology in Kosova, also every homeroom teacher informed the parents regarding the screening, they were allowed to withdraw at any time.

Data collection consisted of steps:

1) Data collection from the questionnaires obtained during the screening in schools.

2) Data collection from the reports of subjects referred for further treatment based on their visual acuity at the screening.

Myopia as a refractive anomaly is the dependent variable and the independent variables are the factors that play an important role in the appearance of myopia such as heredity, socio-economic condition of the parents, late identification and treatment, poor eye care services in the area and other influencing factors.

We used SPSS 12.0 for the statistical analysis of the collected data. Statistical parameters calculated were: structure index, arithmetic mean, standard deviation, maximum and minimum value.

For the statistical significance and the difference between the parameters in the parametric data we have used the T-test, while for the non-parametric data we have used the $\mathrm{Z}$-value, $\mathrm{X}^{2}$ test and Fisher's test.

\section{Results}

On the screening of pre-school and school children for refractive anomalies, were included 1027 subjects of ages 3 - 9 years old. On gender basis, out of 1027 children $536(52.2 \%)$ were male and (47.8\%) were female. $\mathrm{X}^{2}$-test shows no statistical significance between the male and female subjects (Figure 1).

Based on the age group, out of 1027 children screened, 142 were 3 years old, 151 were 4 years old, 169 were 5 years old, 196 children were 6 years old, 131 children were 7 years old, 115 children were 8 years old and 123 children were 9 years old. The highest number of subjects was of age 6 years old with 196 subjects out of 1027 or $19.08 \%$ (Table 1).

Out of the overall number of subjects ( $\mathrm{n}-1027) 16.4 \%$ or 168 were identified to possibly have refractive anomalies, therefore they were referred for further examination at the Eye Clinic, for a final diagnosis.

Statistically, the prevalence of refractive anomalies in the total population

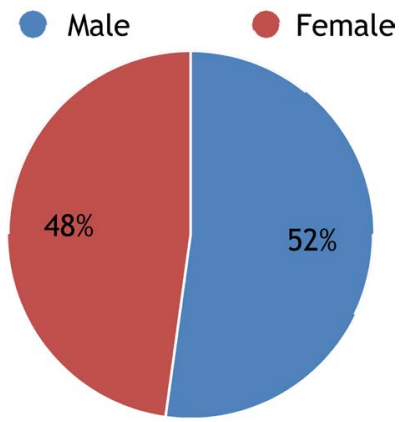

Figure 1. Prevalence of refractive anomalies based on the gender. 
studied is significant based on the resulting value $(\mathrm{P}<0.0001)$. In general, the prevalence of refractive anomalies in this study results 164/103 with an interval of 141/103 in 186/103 for $95 \%$ CI.

Based on the age, out of 168 patients identified with refractive anomalies, the prevalence of refractive anomalies was $9.9 \%$ or 14 subjects in the patients of age 3 and $21.4 \%$ or 28 subjects on the patients of age 7 (Table 1 ).

The prevalence of the refractive anomalies was higher on the male gender $17.2 \%$ compared to that of the female gender with $15.5 \%$ but without any statistical significance.

Out of 168 subject referred for a second visit at the eye clinic only 138 subjects or $82.14 \%$ showed up for the second visit.

77 of them were male and 61 were female. $\mathrm{X}^{2}$-test showed no statistical significance based on the gender $\left(\mathrm{X}^{2}\right.$-test $=1.92, \mathrm{P}=0.217$ so $\left.\mathrm{P}>0.05\right)$ (Figure 2).

Out of 138 children came to a second visit, 114 were confirmed to have refractive anomalies, 4 were diagnosed with other eye pathologies and 20 were not diagnosed with refractive anomalies (Figure 3).

The prevalence of myopia as a specific refractive anomaly was present in 33 cases out of 114 or $3.4 \%$. Other patients were diagnosed with hypermetropia 37 cases or $3.8 \%$ and with astigmatism 44 cases or $4.5 \%$ (Figure 4 ).

Out of 33 cases with myopia, 20 cases (60\%) were diagnosed with a mild

Table 1. Prevalence of refractive anomalies based on the age of the subjects screened (first visit).

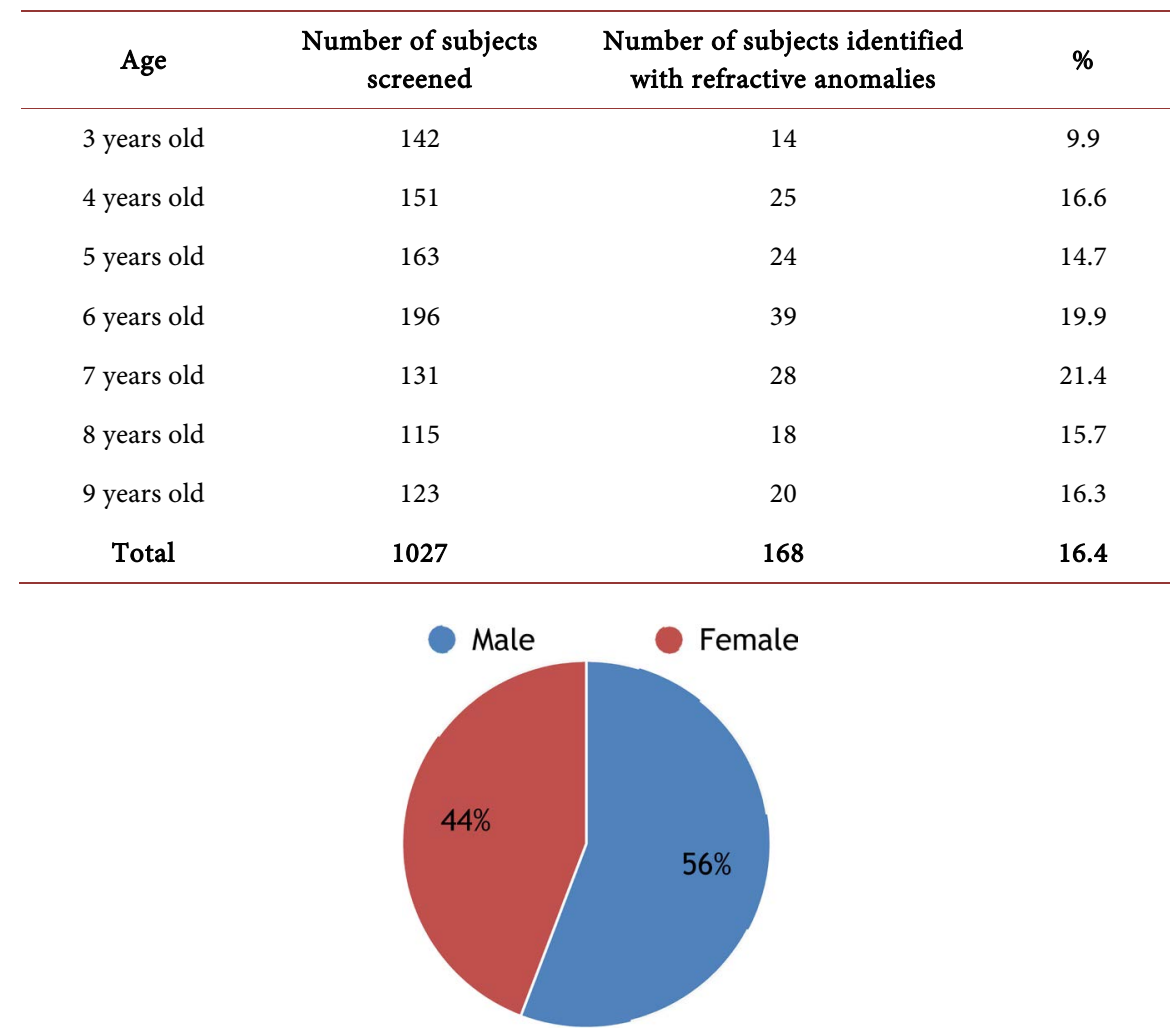

Figure 2. The percentage of the subjects who came to the second visit based on gender. 
degree myopia (myopia of first degree or -1.0 to -3.0 DS). In the age group 3 - 6 years old were in total 6 cases diagnosed with mild myopia 4 were of male and 2 were female. In the age group 6 - 9 years old were in total 14 cases, 9 male and 5 female.

13 cases were diagnosed with intermediate degree myopia ( -3 to -6 DS). 2 cases were of age group 3 - 6 years old, 1 female and 1 male, while 11 cases were of age 6 - 9 years old, 5 male and 6 female.

There were no cases with severe myopia identified in this study (Table 2).

Out of 33 cases of myopia (66 eyes -33 patients $\times 2$ eyes), 9 eyes were also accompanied by strabismus (Figure 5 ).

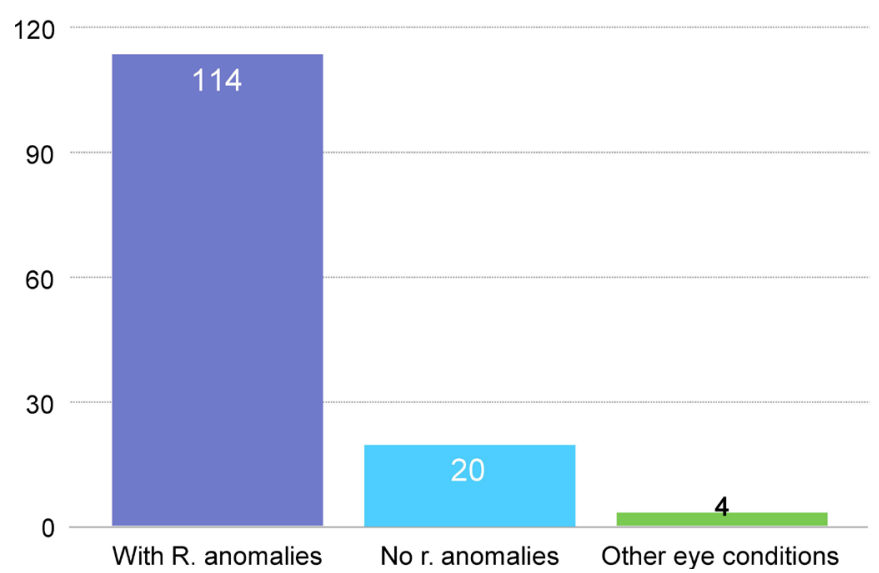

Figure 3. Cases with refractive anomalies after the second visit.

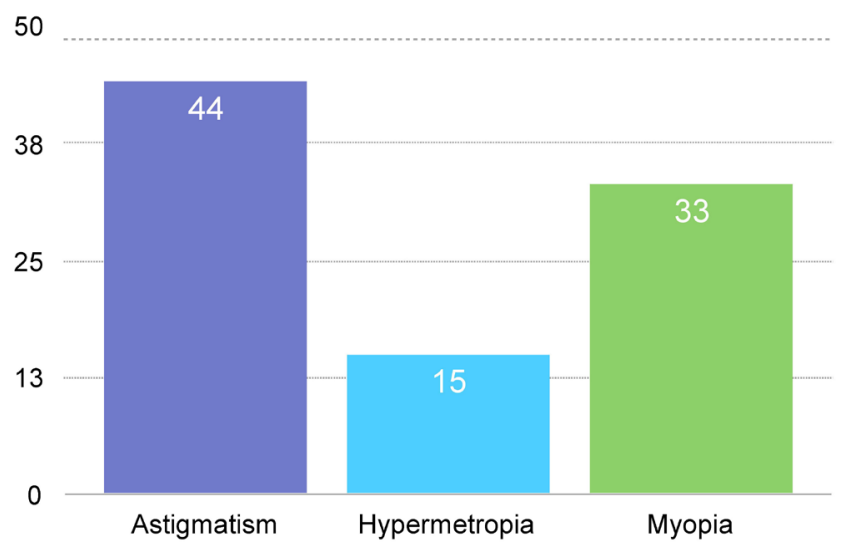

Figure 4. Prevalence of myopia and other refractive anomalies in this study.

Table 2. Number of subjects with different degrees of myopia based on age \& gender.

\begin{tabular}{cccccc}
\hline \multirow{2}{*}{ Degree } & \multicolumn{2}{c}{$3-\mathbf{6}$ y.o } & \multicolumn{2}{c}{ 6-9 y.o } & \multirow{2}{*}{ Total } \\
\cline { 2 - 5 } & Female & Male & Female & Male & \\
\hline Mild Myopia & 2 & 4 & 5 & 9 & 20 \\
Intermediate Myopia & 1 & 1 & 6 & 5 & 13 \\
Severe myopia & 0 & 0 & 0 & 0 & 0 \\
Total & $\mathbf{3}$ & $\mathbf{5}$ & 11 & $\mathbf{1 4}$ & 33 \\
\hline
\end{tabular}


Out of 9 eyes with strabismus, 5 eyes were with exodeviation (divergent strabismus) and 4 eyes with esodeviation (convergent strabismus).

In the above mentioned subjects ( 9 eyes with strabismus and myopia), the binocular vision was not present in 4 eyes of the subjects with slight degree myopia and in 5 eyes of the subjects with intermediate degree myopia (Figure 6).

18 cases of myopia or $55.5 \%$ were diagnosed for the first time during the screening, 15 cases or $44.5 \%$ were diagnosed prior to this screening (Figure 7).

Myopia in one or more family members of our subjects was present in 25 subjects or $75.8 \%$, while 8 subjects did not have a family member with the same refractive anomaly (Figure 8).

Eyes without strabismus

Strabismus

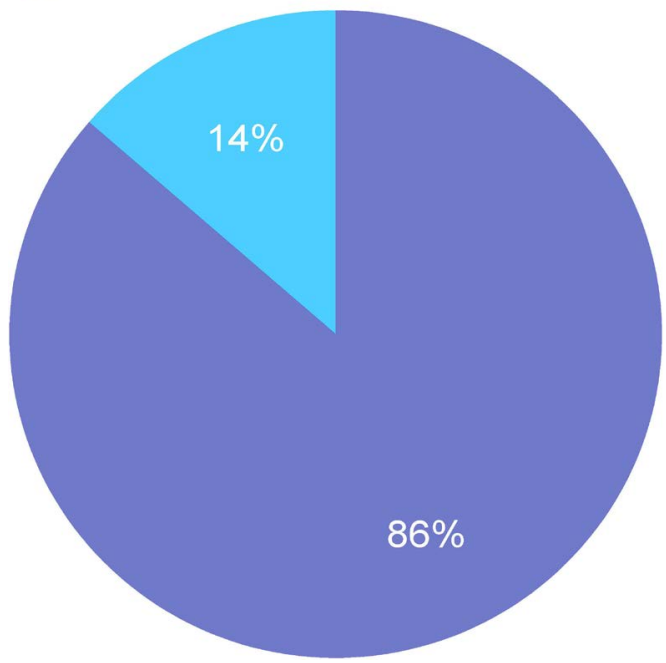

Figure 5. Number of eyes with \& without strabismus.

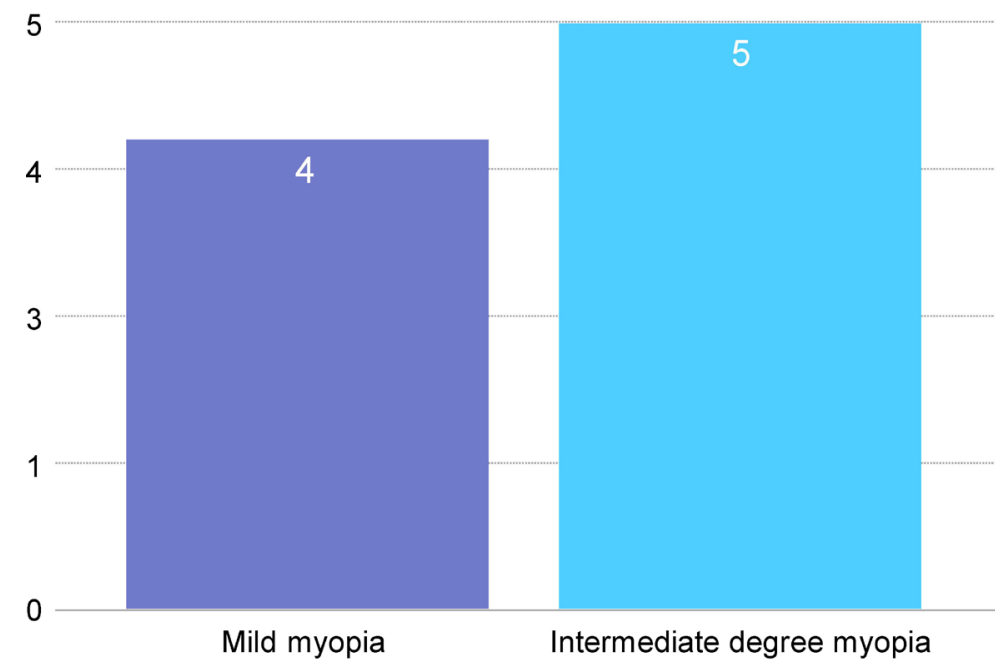

Figure 6. Lack of binocular vision in the eyes with low degree and intermediate degree myopia. 


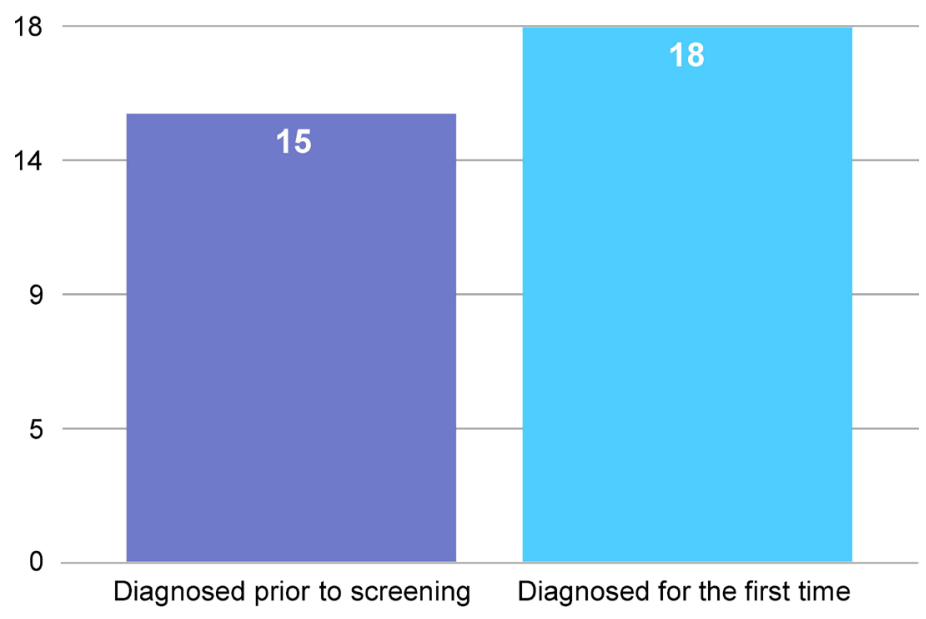

Figure 7. Number of cases diagnosed for the first time.

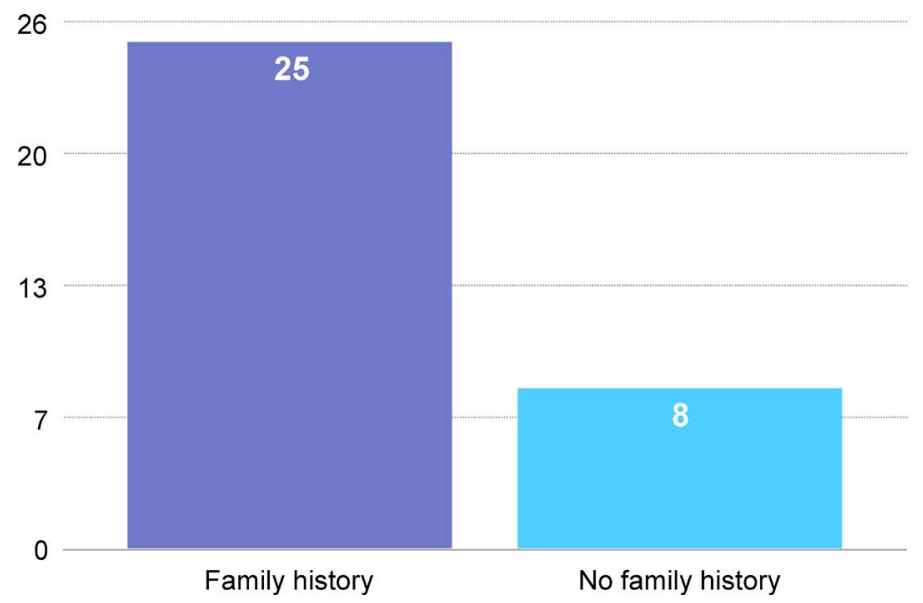

Figure 8. Subjects with family history of myopia.

\section{Discussion}

Refractive anomalies are considered among the main causes of visual problems all around the world and are responsible for a high degree of low vision acuity and vision loss [8].

The prevalence of myopia increases in school-age and young adult cohorts, reaching 20 - 25 percent in the mid to late teenage population and 25 - 35 percent in young adults in the United States and developed countries [9] [10].

Myopia is reported to be higher in some areas of Asia [11].

Studies related to refractive anomalies have shown statistical significance in many different countries [12]-[23].

Population studies on refractive anomalies in Kosovo are limited.

Some studies have found a slightly higher prevalence of myopia in females than in males. However our study shows a slightly higher prevalence in the male gender.

Studies in Australia and New Zealand show that the prevalence of myopia is low (5\%) in children 8 years old and younger. [23]-[28] However, studies in Asia 
show a much higher prevalence of myopia compared to the above mentioned countries. A study in Taiwan which included 10000 school children showed a prevalence of myopia of 6\% in children of age 6-12 years old.

For comparison, myopia is reported in less than $2 \%$ of school children in Australia (age 6 - 7 years old) (13), in 6.6\% of Afro-American children (age 6 72 months), $3.7 \%$ in hispanic children (age $6-72$ months) and only $0.7 \%$ in caucasian children (age 6 - 71 months) [29].

The prevalence of myopia in a study conducted by Chung et al. resulted to be $37 \%$ in the group age $6-12$ years old and $50 \%$ in the group age 13 - 18 years old [30].

\section{Conclusions}

The screening from which the data were obtained included 1027 subjects of ages 3 - 9 years old, from the pre-schools and primary schools in Prishtina during 2010-2011.

The prevalence of refractive anomalies in children 3 - 9 years old resulted in $11.7 \%$ with $95 \%$ CI.

Prevalence of myopia as a specific refractive anomaly was present in $3.4 \%$ of the cases or in 33 subjects.

There was no statistical significance between the male and female subjects.

Out of 33 cases with myopia, 20 cases or $60 \%$ were diagnosed with a mild (low degree) myopia (myopia of first degree or -1.0 to -3.0 DS). In the age group 3 6 years old, total 6 cases were diagnosed with mild myopia 4 were of male and 2 were female. In the age group 6 - 9 years old were in total 14 cases, 9 male and 5 female.

13 cases were diagnosed with intermediate degree myopia ( -3 to -6 DS). 2 cases were of age group 3 - 6 years old, 1 female and 1 male, while 11 cases were of aged 6 - 9 years old, 5 male and 6 female.

There were no cases with severe myopia identified in this study.

18 cases of myopia or $55.5 \%$ were diagnosed for the first time during the screening, 15 cases or $44.5 \%$ were diagnosed prior to this screening.

Myopia in one or more family members of our subjects was present in 25 subjects or $75.8 \%$, while 8 subjects did not have a family member with the same refractive anomaly.

\section{Conflicts of Interest}

The authors declare no conflicts of interest regarding the publication of this paper.

\section{References}

[1] Goss, D.A., Grosvenor, T.P., Keller, J.T., Tootle, W.M., Norton, T.T. and Zadnik, K. (1997) Optometric Clinical Practice Guideline Care of the Patient with Myopia. American Optometric Association, Saint Louis. 
https://www.aoa.org/documents/optometrists/CPG-15.pdf

[2] Carr, B.J. and Stell, W.K. (2017) The Science behind Myopia. In: Kolb, H., Fernandez, E. and Nelson, R., Eds., Webvision: The Organization of the Retina and Visual System, U.S. University of Utah Health Sciences Center, Salt Lake City. https://www.ncbi.nlm.nih.gov/books/NBK470669

[3] Fletcher, M.C. and Brandon, S. (1955) Myopia of Prematurity. American Journal of Ophthalmology, 40, 474-481. https://doi.org/10.1016/0002-9394(55)90548-1

[4] Drillen, C.M. (1964) The Growth and Development of the Premature Born Infant. Williams \& Wilkins, Baltimore, 83-107.

[5] Gwiazda, J., Thorn, F., Bauer, J. and Held, R. (1993) Emmetropization and the Progression of Manifest Refraction in Children Followed from Infancy to Puberty. Clinical Vision Science, 8, 337-344.

[6] Goss, D.A. and Jackson, T.W. (1996) Clinical Findings before the Onset of Myopia in Youth: 4. Parental History of Myopia. Optometry and Vision Science, 73, 279-282. https://doi.org/10.1097/00006324-199604000-00010

[7] Lin, L.-K., Chen, C.-J., Hung, P.-T. and Ko, L.-S. (1988) Nationwide Survey of Myopia among Schoolchildren in Taiwan, 1986. Acta Ophthalmologica, 66, 29-33. https://doi.org/10.1111/j.1755-3768.1988.tb02657.x

[8] Dandona, R. and Dandona, L. (2001) Refractive Error Blindness. Bulletin of the World Health Organization, 79, 237-243.

[9] Hirsch, M.J. (1952) The Changes in Refraction between the Ages of 5 and 14-Theoretical and Practical Considerations. American Journal of Ophthalmology, 29, 445-459. https://doi.org/10.1097/00006324-195209000-00001

[10] Fledelius, H.C. (1983) Is Myopia Getting More Frequent? A Cross-Sectional Study of 1416 Danes Ages 16 Years +. Acta Ophthalmologica, 61, 545-559. https://doi.org/10.1111/j.1755-3768.1983.tb04344.x

[11] Wold, K.C. (1949) Hereditary Myopia. Archives of Ophthalmology, 42, 225-237. https://doi.org/10.1001/archopht.1949.00900050231001

[12] Negrel, A.D., Maul, E., Pokharel, G.P., et al. (2000) Refractive Error Study in Children: Sampling and Measurement Methods for a Multi-Country Survey. American Journal of Ophthalmology, 129, 421-426. https://doi.org/10.1016/S0002-9394(99)00455-9

[13] Gilbert, C. and Foster, A. (2001) Childhood Blindness in the Context of Vision 2020-The Right to Sight. Bulletin of the World Health Organization, 79, 227-232.

[14] Zhao, J., Pan, X., Sui, R., et al. (2000) Refractive Error Study in Children: Results from Shunyi District, China. American Journal of Ophthalmology, 129, 427-435. https://doi.org/10.1016/S0002-9394(99)00452-3

[15] Pokharel, G.P., Negrel, A.D., Munoz, S.R., et al. (2000) Refractive Error Study in Children: Results from Mechi Zone, Nepal. American Journal of Ophthalmology, 129, 436-444. https://doi.org/10.1016/S0002-9394(99)00453-5

[16] Maul, E., Barroso, S., Munoz, S.R., et al. (2000) Refractive Error Study in Children: Results from La Florida, Chile. American Journal of Ophthalmology, 29, 445-454. https://doi.org/10.1016/S0002-9394(99)00454-7

[17] Dandona, R., Dandona, L., Srinivas, M., et al. (2002) Refractive Error in Children in a Rural Population in India. Investigative Ophthalmology \& Visual Science, 43, 615-622.

[18] Murthy, G.V., Gupta, S.K., Ellwein, L.B., et al. (2002) Refractive Error in Children 
in an Urban Population in New Delhi. Investigative Ophthalmology \& Visual Science, 43, 623-631.

[19] Naidoo, K.S., Raghunandan, A., Mashige, K.P., et al. (2003) Refractive Error and Visual Impairment in African Children in South Africa. Investigative Ophthalmology \& Visual Science, 44, 3764-3770. https://doi.org/10.1167/iovs.03-0283

[20] He, M., Zeng, J., Liu, Y., Xu, J., et al. (2004) Refractive Error and Visual Impairment in Urban Children in Southern China. Investigative Ophthalmology \& Visual Science, 45, 793-799. https://doi.org/10.1167/iovs.03-1051

[21] Goh, P., Abqariyah, Y., Pokharel, G.P., et al. (2005) Refractive Error and Visual Impairment in School-Age Children in Gombak District, Malaysia. Ophthalmology, 112, 678-685. https://doi.org/10.1016/j.ophtha.2004.10.048

[22] Junghans, B.M. and Crewther, S.G. (2003) Prevalence of Myopia among Primary School Children in Eastern Sydney. Clinical and Experimental Optometry, 86, 339-345. https://doi.org/10.1111/j.1444-0938.2003.tb03130.x

[23] Dobson, V., Fulton, A.B. and Sebris, S.L. (1984) Cycloplegic Refractions of Infants and Young Children: The Axis of Astigmatism. Investigative Ophthalmology \& Visual Science, 25, 83-87.

[24] Mayer, L., Hansen, R.M., Moore, B.D., Kim, S. and Fulton, A.B. (2001) Cycloplegic Refractions in Healthy Children Aged 1 through 48 Months. Archives of Ophthalmology, 119, 1625-1628. https://doi.org/10.1001/archopht.119.11.1625

[25] Young, F.A., Beattie, R.J., Newby, F.J. and Swindal, M.T. (1954) The Pullman Study: A Visual Survey of Pullman Schoolchildren. Part II. American Journal of Ophthalmology, 31, 192-203. https://doi.org/10.1097/00006324-195404000-00005

[26] Junghans, B.M. and Crewther, S.G. (2005) Little Evidence for an Epidemic of Myopia in Australian Primary School Children over the Last 30 Years. BMCOphthalmol, 11, 1. https://doi.org/10.1186/1471-2415-5-1

[27] Junghans, B.M. and Crewther, S.G. (2005) Little Evidence for an Epidemic of Myopia in Australian Primary School Children over the Last 30 Years. BMC Ophthalmology, 5, 1. https://doi.org/10.1186/1471-2415-5-1

[28] Amigo, G., McCarthy, A. and Pye, D. (1976) Visual Characteristics of an Under-Privileged Group of Australian Children. Australian Journal of Optometry, 59, 188-197. https://doi.org/10.1111/j.1444-0938.1976.tb01417.x

[29] Matsumura, H. and Hirai, H. (1999) Prevalence of Myopia and Refractive Changes in Students from 3 to 17 Years of Age. Survey of Ophthalmology, 44, S109-S115. https://doi.org/10.1016/S0039-6257(99)00094-6

[30] Chung, K.M., Mohidin, N., Yeow, P.T., Tan, L.L. and O’Leary, D. (1996) Prevalence of Visual Disorders in Chinese Schoolchildren. Optometry and Vision Science, 73, 695-700. https://doi.org/10.1097/00006324-199611000-00004 